\title{
Evaluation of the community pharmacist's behavior towards a prescription of antidiabetic and antiasthma drugs
}

Muaed J. ALOMAR, Shareef QANDIL, Hanan M.A. AL-HILWANI, Dima M. MALKAT, Claire CAROLINE. Received (first version): $10-$ Sep-2010

Accepted: 27-Feb-2011

\begin{abstract}
${ }^{\star}$
Objective: The objective of this study is to assess the performance of community pharmacist towards antidiabetic and antiasthma prescriptions, and also to assess the lack of information provided by community pharmacists regarding patient counseling and missing data, using a simulated patient technique.

Methods: A prescription including antidiabetic and antiasthma drugs was used by simulated patient to assess community pharmacist's performance in 194 pharmacies. A performance assessment sheet was used to measure the patient counseling process. A quantitative descriptive and comparative analysis was done for the collected data. Pearson chi-square test (crosstabs) was used with a level of significance 95\%).

Results: The analysis of the 194 pharmacies visited revealed that most of the pharmacists were male $(61 \%)$, Arabs (35\%) and Indians (55\%) with some other nationalities. The dispensing time in the pharmacy ranged between 2 to 10 minutes. Spending time with patients was not affected by gender ( $p$-value 0.087 ), slightly affected by nationality ( $p$-value 0.04 ), and highly affected by age ( $p$-value 0.002 ) leaning towards older pharmacists who spent more time with patients than younger pharmacists. Most pharmacists (90\%) started preparing the prescription once they received the prescription with no actual prescription screening. fifty five percent of the pharmacists asked about the duration of the treatment after preparing the prescription. ninety six percent did not counsel patients about diet, exercise and lifestyle changes. Less than $40 \%$ asked if the prescription was intended to be used for the same patient. Conclusion: This study recommends that health authorities consider follow up plans in order to
\end{abstract}

\footnotetext{
*Muaed J. ALOMAR. BSc.(Pharm), MSc.(Clin Pharm), PhD. Clinical Pharmacy Lecturer.; Fujairah, UAE. Clinical Pharmacy Department. Faculty of Pharmacy and Health Sciences. Ajman University of Science and Technology Network. Fujairah, (United Arab Emirates).

Shareef QANDIL. B.Pharm. Outpatient pharmacy supervisor and diabetic counseling coordinator. Tawam Hospital. Al-Ain, (United Arab Emirates).

Hanan M.A. AL-HILWANI. B.Pharm. Ajman University of Science and Technology Network. Fujairah, (United Arab Emirates).

Dima M. MALKAT. B.Pharm. Ajman University of Science and Technology Network. Fujairah, (United Arab Emirates).

Claire CAROLINE. Strauch. B.Pharm. Ajman University of Science and Technology Network. Fujairah, (United Arab Emirates).
}

ensure the best pharmaceutical care is provided by community pharmacies.

Keywords: Medication Errors. Community Pharmacy Services. Professional Practice. United Arab Emirates.

\section{EVALUACIÓN DEL COMPORTAMIENTO DE LOS FARMACEUTICOS COMUNITARIOS ANTE UNA PRESCRIPCIÓN DE ANTIDIABÉTICOS Y ANTIASMÁTICOS}

\section{RESUMEN}

Objetivo: El objetivo de este estudio es evaluar la actuación de los farmacéuticos comunitarios ante una prescripción de antidiabéticos y antiasmáticos, así como evaluar la falta de información proporcionada por los farmacéuticos comunitarios en relación al consejo a paciente y datos omitidos, utiizando una técnica de paciente simulado. Métodos: Un paciente simulado utilizó una receta que incluía medicamentos antidiabéticos y antiasmáticos para evaluar la actuación de los farmacéuticos comunitarios en 194 farmacias. Para medir el proceso de aconsejamiento del paciente, se utilizó una hoja de control de actuación. Con los datos recogidos se realizó un análisis descriptivo cuantitativo. Se utilizaron pruebas chi-cuadrado de Pearson (crosstabs) con un nivel e significación del 95\%.

Resultados: El análisis de las 194 farmacias visitadas reveló que la mayoría e los farmacéuticos eran hombres (61\%), árabes (35\%) e Indios (55\%) con algunas otras nacionalidades. El tiempo de dispensación en la farmacia osciló entre 2 y 10 minutos. El tiempo pasado con los pacientes no estuvo afectado por el género $(\mathrm{p}=0,087)$,

ligeramente afectado por la nacionalidad $(\mathrm{p}=0,04)$, y altamente afectado por la edad $(\mathrm{p}=0,002)$, aumentando hacia los mayores farmacéuticos, que pasaban más tiempo que los jóvenes. La mayoría de los farmacéuticos $(90 \%)$ comenzó preparando la receta, una vez que la recibían, sin rastreo del perfil real. El 55\% de los farmacéuticos preguntó sobre la duración del tratamiento después de preparar la receta. El 96\% no aconsejó a los pacientes sobre dieta, ejercicio y cambios en hábitos de vida. Menos del $40 \%$ preguntó si la receta era ara ser usada por el mismo paciente.

Conclusión: Este estudio recomienda que las autoridades sanitarias consideren planes de seguimiento para asegurar que se proporciona la 
mejor atención farmacéutica en las farmacias comunitarias.

Palabras clave: Errores de medicación. Servicios de Farmacia Comunitaria. Práctica Profesional. Emiratos Árabes Unidos.

\section{INTRODUCTION}

The dispensing function of the pharmacist, while important and even vital for patient care, is essentially a superficial practice of the profession which, by itself, does not utilize knowledge or skills sufficiently basic to merit that lies within the grasp of clinical pharmacists. ${ }^{1}$ Pharmaceutical care is a type of pharmaceutical practice that revolves around a relationship between a patient and a pharmacist in which the pharmacist performs drug use control functions governed by awareness of and commitment to the patient's interest. ${ }^{1}$ The basis of pharmaceutical care is responsibility and accountability to patients for the outcome of their drug therapy. The overall goal of pharmaceutical care is to maintain patients at the highest possible level of functional and psychosocial well-being through optimal management of drug therapy. Pharmaceutical care requires continuity of care between different practice settings. Three major functions of pharmacist in providing pharmaceutical care; identifying potential and actual drug related problems, resolving actual drug related problems and preventing potential drug related problems. ${ }^{2}$ To deliver a pharmaceutical care plan, a professional relationship between the pharmacist and the patient must be established and maintained, patient specific clinical information must be gathered, classified, saved and maintained, patient specific clinical information must be evaluated and a drug therapy plan developed with the patient. The pharmacist must make sure that the patient has all the tools and information needed to follow the drug therapy plan. The pharmacist must screen, monitor, and modify the therapeutic plan as necessary and appropriate, in concert with the patient. ${ }^{1-3}$

Patient counseling is a very important part of the pharmaceutical care model. Implementation of a pharmaceutical care plan in the community pharmacy, and monitoring of therapeutic outcomes, requires giving patients all the needed information and any lifestyle changes in order to accomplish successful pharmacotherapeutic goals. ${ }^{4}$ The pharmacy profession is increasingly encouraging pharmacists to offer pharmaceutical care to improve patients' health, rather than simply dispensing medications. Pharmacist's descriptions of pharmaceutical care include "educating patients on medicines and disease states and telling patients why they take a medicine, the effects, the side effects, outcomes and checking medication compliance". 5

Implementing pharmaceutical care is affected by country regulations which may either oblige pharmacists to practice pharmaceutical care or has no regulations regarding this. The pharmacy business itself might encourage pharmacists to provide pharmaceutical care service for the purpose of publicity and marketing of their business. The age of the responsible pharmacist also plays a crucial role in providing pharmaceutical care services. ${ }^{6,7}$ To implement pharmaceutical care under such circumstances and its effects is considered a challenge to pharmacy associations, managers, and individual pharmacists who are in a position to improve this element of patient care. ${ }^{8}$ Programs which help pharmacists to assess their work environment and determine strategies to impact or reconstruct their environments are required. ${ }^{9}$ Pharmacists and patients identified several obstacles for implementing pharmaceutical care within the community pharmacy environment. These obstacles are: Lack of time required to provide pharmaceutical care, lack of private counseling space and lack of direct access to physicians. Pharmacists provide the greatest amount of counseling for new prescriptions, drugs with complicated instructions, or medications for children. When a refill prescription is considered, most pharmacists assume "the patient already knows how to use the medications," and that most customers "don't want and don't expect" counseling. ${ }^{10}$ Pharmaceutical care activities include monitoring patients' symptoms, counseling patients regarding their medications, helping discovering and resolving drug-related problems, establishing pharmacist-physician inter-professional communication, and performing patient-specific interventions if needed. ${ }^{11}$

Pharmacists need to go beyond traditional sendermessage-receiver communication models in counseling patients and adopt a problem-solving approach through which each patient's needs and level of understanding are taken into account. ${ }^{10}$ Pharmacists in Moldova appear to be more concerned about the traditional approach to the practice of pharmacy, concentrating mainly on the dispensing practice approach rather than pharmaceutical care, drug information and selfcare. ${ }^{12}$ In Brazil pharmacists are not able to interpret drug related information for pregnant women, and they lack the reliable resources for drug information. ${ }^{13}$ In the UAE, pharmacists lack the concept of pharmaceutical care and patient counseling. This shortage in implementing patient care affects therapeutic outcomes and leads to more drug related problems. In this study, testing of pharmacist's behavior in offering proper patient counseling clarifies the weaknesses and threats of pharmacists in the UAE. This testing will be carried out using a simulated patient approach. As simulated patient is an individual who is trained to act as a real patient in order to simulate a set of medical symptoms. Simulated patients have been used in many aspects, including education, assessment, and research studies. ${ }^{14}$

The objective of this study is to assess the performance of community pharmacist's behavior towards antidiabetic and antiasthma prescriptions, and also to assess the lack of information provided by community pharmacists regarding patient counseling and missing data. 


\section{METHODS}

A simulated patient in which a patient's prescription for antidiabetic and antiasthma medications was used in order to evaluate the reaction of the community pharmacist towards this prescription. The prescription included the following medications as shown in figure 1; Donil® (glibenclamide) $5 \mathrm{mg}$, Glucophage $\AA$ (metformine) 500 mg, Ventolin ${ }^{\circledR}$ (salbutamol) inhaler, Prednisolone $5 \mathrm{mg}$. This prescription was prescribed to a patient suffering from both asthma and diabetes mellitus. One hundred and ninety four pharmacies were visited by a simulated patient in order to dispense the prescription taking into consideration the following areas in the UAE; Abu Dhabi, Dubai, Sharjah, and Fujairah. The research was intended to cover every accessible pharmacy in those areas within the time frame of the study. The study was carried out in the period between January and April 2010. One of the research team went as a simulated patient. This person visited the pharmacies in order to dispense the prescription. Once the pharmacist delivered all of the medications, the researcher assessed the behavior of the pharmacist according to Performance assessment sheet shown in table 1. The prescription was missing certain information such as the duration of treatment, directions for use, age and also prednisolone was a medication error which may worsen diabetes mellitus.

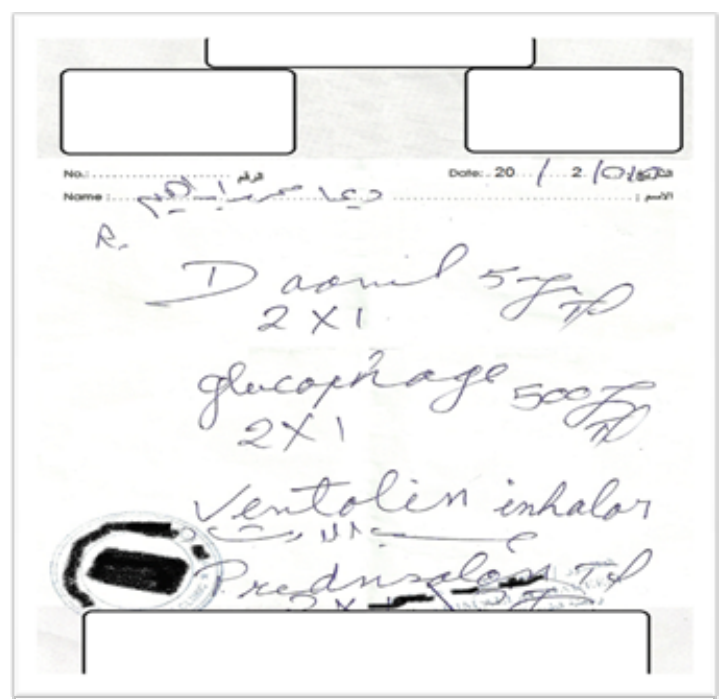

Figure 1. Prescription containing 4 medicines for patient with asthma and diabetes.

When this prescription is dispensed, the following actions should be accomplished according to ASHP guidelines; first; the pharmacist should check the possibility of pregnancy or breast feeding since the simulated patient is female. Second; prescription screening regarding drug-drug interaction should be done. Third; patient counseling about the proper use of Ventolin $\AA$ inhaler, pharmacist should implement the "show and tell" technique in order to educate the patient about the proper use of the applicator. Fourth; filling in the gap technique should be followed in order to make sure the patients has the appropriate information about diabetes. Diabetes complications should also be addressed to the patient. Fifth; patients must learn about what to expect from the medication so that they can monitor the consequences. Sixth; patients should learn about the most possible side effects which might hurt them including hypoglycemia, GIT disturbances due to metformine and glibenclamide, peptic ulcer in case of prednisolone.

The ASHP guidelines on pharmacist-conducted patient education and counseling were used to construct performance assessment sheet (table 1). ${ }^{15}$ The UAE has approximately 400 community pharmacies distributed all over the country. ${ }^{16} 194$ pharmacies in Abu Dhabi, Dubai, Sharjah, and Fujairah were included in the study.

A prospective quantitative descriptive and comparative analysis was done for the collected data. To test the effect of a pharmacist's gender on the average time spent with patients, Pearson chisquare test (crosstabs) was used with a level of significance $95 \%$.

Table 1; Performance assessment sheet

Pharmacist's gender, age and nationality

Dispensing time; defined as the time spent by the patient from the moment of entering the pharmacy to the moment of leaving it.

Location of the pharmacy: Abu Dhabi, Dubai, Sharjah or Fujairah

Pharmacist's reaction while reading the prescription

Did the pharmacist dispense the prescription directly without asking any question

Pharmacist - physician interaction

Did the pharmacist ask about patient's health condition

Did the pharmacist ask about pregnancy status

Did the pharmacist ask if the patient taking any other medications

Did the pharmacist explain how to use the medication (Doses, after/before/with meal)

Did the pharmacist explain medication dose

Did the pharmacist explain how to use inhaler, if yes, did the pharmacist give the right information

Did the pharmacist advice the patient about diet \& exercise changes

Did the pharmacist ask if asthma gets worse by any kind of action

Did the pharmacist ask about the onset of asthma

Did the pharmacist ask about the onset of diabetes

Did the pharmacist ask about the level of blood glucose

Did the pharmacist counsel the patient about the proper use of prednisolone

Did the pharmacist ask for whom is the medication

\section{RESULTS}

The analysis of the 194 pharmacies visited during the study revealed that most of the pharmacists were male (61\%), Arabs (35\%), Indians (55\%), Philippines (5\%), Pakistan (2\%), Iranians (2\%), Chinese and Nigeria (1\%). The aforementioned pharmacists were from the following age groups: $25-35$ (41\%), 35-45(49\%) and above 45 (10\%). The distribution of the selected pharmacies among the $\mathrm{UAE}$ is shown in table 2. Figure 2 illustrates the dispensing time in the pharmacy which was variable ranging between 2 to 10 minutes. Spending time with the patient was not affected by gender ( $p$-value 0.087 ), slightly affected by nationality ( $p$-value 0.04 ), and highly affected by age ( $p$-value 0.002 ) leaning towards older pharmacists who spent more time with patients than the younger pharmacists. 


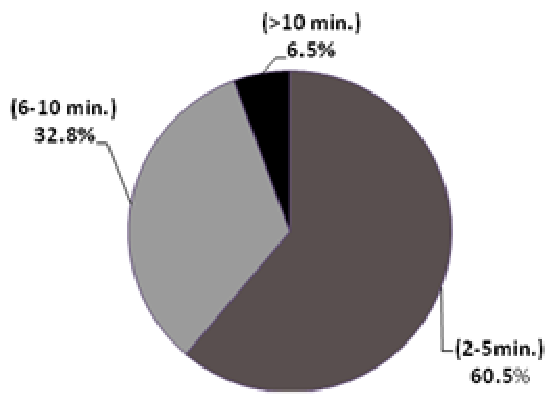

Figure 2; dispensing time

Most pharmacists (90\%) started preparing the prescription once they received it with no concern towards the missing data or medications errors (i.e. no prescription screening was performed). $55 \%$ of the pharmacists asked about the duration of the treatment after preparing the prescription, only $9 \%$ advised the patient to contact the physician in order to determine the duration of therapy and 30\% dispensed the medication to the patient regardless of the duration of therapy. Only $15 \%$ of the pharmacists asked about the health status of the patient, 3\% asked if the patient was using any other medications and 6\% asked about pregnancy status.

\begin{tabular}{|l|c|c|}
\hline \multicolumn{3}{|c|}{ Table 2. Pharmacy location in the United Arab Emirates } \\
\hline Location & Frequency & Percent (\%) \\
\hline Abu dhabi & 20 & 10.3 \\
\hline Dubai & 72 & 37.1 \\
\hline Sharjah & 90 & 46.4 \\
\hline Al fujairah & 12 & 6.2 \\
\hline
\end{tabular}

With regards to explaining the correct way to use the inhaler, only $58 \%$ of the pharmacists gave their advice but none of them used show and tell technique. Regarding the use of oral medications, table 3 shows the exact response of pharmacists towards the prescription which reflects a wide variation in the way of dealing with these medications. Counseling about diet and exercise doesn't seem to be considered a part of the pharmacist's responsibilities, $96 \%$ of the pharmacist didn't mention anything regarding this issue. For prednisolone, table 4 shows the variation in pharmacist's behavior which had influence on the amount of medication need to be given to the patient, since the exact amount was not mentioned in the prescription and considered missing data. Less than $40 \%$ of the pharmacists asked if the prescription intended to be used for the same person who brought in or if she was buying it for somebody else. Only $2 \%$ asked the researcher if the asthma is made worse by any kind of action or strenuous activity and only $6 \%$ asked about the onset of asthma. Referring to the standard use of the prescribed medications only $35 \%$ gave the right information regarding the dose and frequency. Neither the gender (male or female) of the pharmacists nor the nationality has shown any difference in the counseling process.

\section{DISCUSSION}

The use of simulated patients in clinical literature is not a recent issue, for more than 40 years, simulation has proven to be an important approach in the analysis of many health care delivery systems. ${ }^{17}$ Simulation is a process of designing and creating a patient model in order to identify a specific medical issue before it actually happens to an actual patient. ${ }^{18} \mathrm{~A}$ study using simulated patient done in Malaysia to assess the response of pharmacists towards a request for back pain medication, revealed that pharmacists need to spend more quality time with patients before dispensing any medication. ${ }^{19}$ Using a simulated patient method in teaching enhances the ability of students to understand all dimensions of pharmacotherapy and patient counseling. ${ }^{20}$ Audio taping simulated patient techniques also showed successful results in analyzing patient medical situation. $^{21}$ In order to avoid the problems in implementing research methodologies based on patients and health care providers, simulated patients are considered one of the best methods of assessing professional performance in clinical settings. ${ }^{22}$ The use of a simulated patient technique to assess pharmacist's behavior is well documented and widely used in the medical field. ${ }^{22}$ This method enables professional pharmacists to accurately assess the process of patient counseling during medication dispensing. It is also used in the process of education and can play an important role in the pharmacy curriculum, complementing practitionereducators in exposing students to real world context for better understanding of pharmaceutical care. ${ }^{23}$ Using simulated patients in this study showed many defect in the process of patient counseling and its implementation in the community pharmacy setting.

For implementing patient counseling, many factors need to be considered including pharmacists pharmacological knowledge, attitude, communication skills, listening skills, show and tell skills, fill in the gap skills and inter-professional communication skills with other medical professionals like physicians, pharmacists, nurses and lab analysts. It is well documented in this study that community pharmacists in the UAE lack many of these factors.

The selection of antidiabetic and antiasthma prescription was due to a recent WHO report on the burden of disease estimating that diabetes in the UAE is 1,024 per 100,000, one of the highest in the world. ${ }^{24}$ Continuous follow up and comprehensive counseling may be a major factor in reducing medication errors and also prevention of complications. For that reason it is important to emphasize lifestyle changes and quality of life among asthmatic and diabetic patients. Patients need to be well-educated about the proper use of the medications and alert about signs of complications in order to ensure better quality of life.

Pharmacists carry a very important role in providing patient consultation and work as patient educators; a simple intervention in community pharmacies, incorporating daily reminders via inhaler technique and labels on inhalers, can lead to improvement in inhaler technique and asthma outcomes. ${ }^{10,25}$

Incorrect usage of inhaler devices might have a major impact on the clinical efficacy of the delivered medication. ${ }^{26,27}$ The show and tell technique must be well utilized in order to educate patients about the proper use of these tools. 


\begin{tabular}{|c|c|c|}
\hline Pharmacist's response & $\mathrm{N}$ & $\%$ \\
\hline $\begin{array}{l}\text { Daonil: } 1 \text { tablet in the morning and in the evening before meals, Glucophage: } 1 \text { tablet in the } \\
\text { morning and in the evening. Prednisolone: } 1 \text { tablet in the morning and in the evening before meals. }\end{array}$ & 12 & 6.2 \\
\hline 1tablet in the morning and in the evening from each medication and given after meal & 32 & 16.5 \\
\hline 2 tablets together before meals in the morning from each medication & 13 & 6.7 \\
\hline Twice daily from each drug without explanation & 37 & 19.1 \\
\hline Twice daily before meals & 28 & 14.4 \\
\hline Didn't mention anything about frequency and the dose until patient asked & 12 & 6.2 \\
\hline Daonil \& Glucophage:2 tablets together after meal, Prednisolone:2 tablets together at night & 4 & 2.1 \\
\hline $\begin{array}{l}\text { Daonil: } 2 \text { tablets together before meals, Glucophage:2 tablets together after meal. Prednisolone :2 } \\
\text { tablets together at night }\end{array}$ & 12 & 6.2 \\
\hline Don't know, Didn't give any advice & 7 & 3.6 \\
\hline Didn't say anything & 11 & 5.7 \\
\hline Daonil \& Glucophage: 2 tab. together & 1 & 0.5 \\
\hline 2 tablets together after meals & 3 & 1.5 \\
\hline 2 tablets together without explanation & 20 & 10.3 \\
\hline
\end{tabular}

\begin{tabular}{|l|c|c|}
\hline \multicolumn{1}{|c|}{ Table 4. Pharmacist's behavior regarding the amount of prednisolone need to be dispensed } \\
\hline \multicolumn{1}{|c|}{ Pharmacist's behavior } & $\mathrm{N}$ & $\%$ \\
\hline the pharmacist told the patient no need for prednisolone & 4 & 2.1 \\
\hline the pharmacist gave the patient 2 boxes enough for 1 month & 142 & 73.2 \\
\hline the pharmacist gave the medication for 5 days & 25 & 12.9 \\
\hline the pharmacist gave the medication for 10 days & 7 & 3.6 \\
\hline the pharmacist gave 1 box for 15 days & 12 & 6.2 \\
\hline $\begin{array}{l}\text { the pharmacist told the patient that prednisolone is contraindicated for } \\
\text { this patient }\end{array}$ & 1 & 0.5 \\
\hline
\end{tabular}

Patients do not have a completely correct inhaler technique, which may lead to less suboptimal dose and suboptimal pharmacotherapeutic outcomes. ${ }^{28}$ Quick and concise counseling techniques are necessary. The instructions can vary according to different dosage forms. Metered dose inhalers (MDIs) require coordination, which can be difficult for preschool children and the geriatrics. The patient needs to exhale first and press down on the canister while inhalation, patient then need to hold breathe for at least 10 seconds. ${ }^{29}$ The medication should not be tasted in the mouth. ${ }^{30}$ Most asthmatic patients were unable to use their inhaler correctly. Education on inhalation technique and using inhaler by a spacer equally enhanced the efficacy of inhaler drugs. ${ }^{31}$ Community pharmacists are ideally placed to implement new strategies that aim to ensure asthma care meets current standards of the best practice. $^{32}$

Both patient assessment and medication counseling were suboptimal compared with recommended practice when medication was supplied in the community pharmacy. ${ }^{33}$ Pharmacy and pharmacist demographic variables do not appear to affect the assessment of asthma control. This research indicates the need for substantial improvements in practice in order to provide medication in line with quality use of medication principles of ensuring safe and effective use of medication. Standardization of patient information is very important which leads to increased patient confidence in the pharmacist's advice and strengthens the patient-pharmacist relationship. ${ }^{34}$ The pharmacist should also counsel and educate the diabetic patients about the need for lifestyle changes that can affect their risks for common chronic diseases. ${ }^{35}$ Physical activity is an effective therapeutic tool in the management of type 2 diabetes. Pharmacists can motivate patients with type 2 diabetes to exercise long-term and emphasize the value of individual behavioral approaches in daily practice. ${ }^{36}$ Physical activity counseling was effective in improving glycemic control as well as the status of cardiovascular risk factors in people with type 2 diabetes. ${ }^{37}$ Glycemic control of type 2 diabetic patients can also be improved through patient counseling regarding disease, medication, diet and exercise. ${ }^{38}$ Community-based resources that provide healthcare services to patients with diabetes offer a practical, patient-empowering, and cost-effective solution to escalating healthcare costs. ${ }^{39} \mathrm{~A}$ community-based intervention program improved the process of cholesterol management in high-risk patients. This program demonstrates the value of community pharmacists working in collaboration with patients and physicians. ${ }^{40,41}$

\section{CONCLUSIONS}

Community pharmacists carry a big responsibility towards a patient's health status. They are the final station in the process of drug therapy. If this responsibility is not fulfilled in the best way, patients will be harmed. To fulfill this responsibility, pharmacists are required to update their pharmacological knowledge on a daily bases, improve their attitude towards patient care and improve their communication skills. Courses about the implementation and importance of pharmaceutical care may help improving the career. Also adopting a motivation plans (including incentives, appreciation letters, career promotion) for those who improve themselves may help make community pharmacy practice more effective in the UAE. This study recommends that health authorities consider follow up plans in order to ensure the best 
pharmaceutical care is provided by community pharmacies.

\section{CONFLICT OF INTEREST}

None declared.

\section{References}

1. Holland RW, Nimmo CM. Transitions, part 1: beyond pharmaceutical care. Am J Hosp Pharm. 1999;56(17):1758-1764.

2. Farris KB, Kirking DM. Assessing the quality of pharmaceutical care. II. Application of concepts of quality assessment from medical care. Ann Pharmacother. 1993;27(2):215-223.

3. Yancey V, Yakimo R, Perry A, Timothy B, McPherson.Perceptions of pharmaceutical care among pharmacists offering compounding services. J Am Pharm Assoc. 2008;48(4):508-514.

4. Candace BW, Nykamp D, Ellington AM. Patient-Guided Counseling in the Community Pharmacy Setting. J Am Pharm Assoc. 2000;40(6):765-772

5. Amsler MR, Murray MD, Tierney WM, Brewer N, Harris LE, Marrero DG, Weinberger M. Pharmaceutical Care in Chain Pharmacies: Beliefs and Attitudes of Pharmacists and Patients. J Am Pharm Assoc (Wash). 2001;41(6):850-855.

6. Montgomery AT, Sporrong SK, Tully MP, Lindblad AK. Follow-up of patients receiving a pharmaceutical care service in Sweden. J Clin Pharm Ther. 2008;33(6):653-662.

7. Uema SA, Vega EM, Armando PD, Fontana D. Barriers to pharmaceutical care in Argentina. Pharm World Sci. 2008;30(3):211-215

8. Heaton PC, Cluxton RJ Jr., Moomaw CJ. Acetaminophen Overuse in the Ohio Medicaid Population. J Am Pharm Assoc. 2002;43(6):680-684

9. Farris KB, Schopflocher DP. Between intention and behavior: an application of community pharmacists' assessment of pharmaceutical care. Soc Sci Med. 1999;49(1):55-66.

10. Knudsen $\mathrm{P}$, Herborg H, Mortensen AR, Knudsen M, Hellebek A. Preventing medication errors in community pharmacy: frequency and seriousness of medication errors. Qual Saf Health Care. 2007;16:291-296.

11. Strand LM, Cipolle RJ, Morley PC, Perrier DG.. Levels of pharmaceutical care: a needs-based approach. Am J Hosp Pharm. 1991;48(3):547-550.

12. Cordina M, Safta V, Ciobanu A, Sautenkova N. An assessment of community pharmacists' attitudes towards professional practice in the Republic of Moldova. Pharm Pract (Internet). 2008;6(1):1-8.

13. Baldon JP, Correr CJ, Melchiors AC, Rossignoli P, Fernandez-Llimos F, Pontarolo R. Community pharmacists' attitudes and knowledge on dispensing drugs to pregnant women. Pharm Pract (Internet). 2006;4(1):38-43.

14. Barrows HS. An overview of the uses of standardized patients for teaching and evaluating clinical skills. Acad Med. 1993;68(6):443-451

15. ASHP guidelines on pharmacist-conducted Patient education and counseling medication therapy and Patient Care: organization and delivery of services-guidelines. 2006; 262-228.

16. Guidelines and minimum standards for good pharmacy practice (GPP) in UAE pharmacies guide to good pharmacy practice (GPP) in UAE pharmacies. 2009.9;1-5.

17. Badri AM, Hollingsworth J. A simulation model for scheduling in the emergency room. Int J Operat Product Manag. 1993;13(3):13-24.

18. Su S, Shih CL. Resource reallocation in an emergency medical service system using computer simulation. Am J Emerg Med. 2002;20(7):627-34

19. Chua SS, Ramachandran CD, Paraidathathu TT. Response of community pharmacists to the presentation of back pain: a simulated patient study. Int J Pharm Pract.2006;14(3):171-178.

20. Darbishire PL, Plake KS, Nash CL, Shepler BM. Active-learning laboratory session to teach the four M's of diabetes care. Am J Pharm Educ. 2009;73(2):22.

21. Werner JB, Benrimoj SI. Audio taping simulated patient encounters in community pharmacy to enhance the reliability of assessments. Am J Pharm Educ. 2008;72(6):136

22. Watson MC, Skelton JR, Bond CM, Croft P, Wiskin CM, Grimshaw JM, Mollison J. Simulated patients in the community pharmacy setting. Using simulated patients to measure practice in the community pharmacy setting. Pharm World Sci. 2004;26(1):32-37.

23. Austin Z, Gregory P, Tabak D. Simulated Patients vs. Standardized Patients in Objective Structured Clinical Examinations. Am J Pharm Educ. 2006;15;70(5):119.

24. World Health Organization: Disease and injury country estimates. 2009 http://www.who.int/healthinfo/global_burden_disease/estimates_country/ en/index.html (accessed Sep-2010)

25. Hope NH, Ray SM, Franks AS, Heidel E. Impact of an educational intervention on steroid prescribing and dosing effect on patient outcomes in COPD exacerbations. Pharm Pract (internet) 2010;8(3):162-166.

26. Gandhi TK, Weingart SN, Seger AC, Borus J, Burdick E, Poon EG, Leape LL, Bates DW. Outpatient prescribing errors and the impact of computerized prescribing. J Gen Intern Med. 2007; 20:837-841.

27. Basheti IA, Reddel HK, Armour CL, Bosnic-Anticevich SZ. Improved asthma outcomes with a simple inhaler technique intervention by community pharmacists. J Allergy Clin Immunol. 2007;119(6):1537-1538

28. Fink JB, Rubin BK. Problems with inhaler use: a call for improved clinician and patient education. Respir Care. 2005;50(10):1360-1374

29. Rubin BK. 2004. What does it mean when a patient says, My asthma medication is not working? Chest. 2004;126(3):972-981. 
30. Stiegler KA, Yunker NS, Crouch MA. Effect of pharmacist counseling in patients hospitalized with acute exacerbation of asthma. Am J Health Syst Pharm. 2003;60(5):473-476.

31. Hollingworth W, Devine EB, Hansen RN, Lawless NM, Comstock BA, Norton JLW. The Impact of e-Prescribing on Prescriber and Staff Time in Ambulatory Care Clinics: A Time-Motion Study. J Am Med Inform Assoc. 2007;14(6):722730.

32. Lewis RK, Lasack NL, Lambert BL, Connor SE. Patient counseling--a focus on maintenance therapy. Am J Health Syst Pharm. 1997;54(18);2084-2098.

33. Bonnabry P, Despont-Gros C, Grauser D, Casez P, Despond M, Pugin D, Rivara-Mangeat C, Koch M, Vial M, Iten A, Lovis C. A risk analysis method to evaluate the impact of a computerized provider order entry system on patient safety. J Am Med Inform Assoc. 2008;15(4):453-460

34. Barber N, Rawlins M, Dean Franklin B.. Reducing prescribing error: competence, control, and culture. Qual Saf Health Care. 2003;12(Suppl 1):i29-32.

35. Lavorini F, Magnan A, Dubus JC, Voshaar T, Corbetta L, Broeders M, Dekhuijzen R, Sanchis J, Viejo JL, Barnes P, Corrigan C, Levy M, Crompton GK. Effect of incorrect use of dry powder inhalers on management of patients with asthma and COPD. Respir Med. 2008;102(4):593-604.

36. Rabe KF, Hurd S, Anzueto A, Barnes PJ, Buist SA, Calverley P, Fukuchi Y, Jenkins C, Rodriguez-Roisin R, van Weel C, Zielinski J; Global Initiative for Chronic Obstructive Lung Disease. Global strategy for the diagnosis, management, and prevention of chronic obstructive pulmonary disease: GOLD executive summary. Am J Respir Crit Care Med. 2007;176(6):532-555.

37. Schneider CR, Everett AW, Geelhoed E, Kendall PA, Clifford RM. Measuring the assessment and counseling provided with the supply of nonprescription asthma reliever medication: a simulated patient study. Ann Pharmacother. 2009 Sep;43(9):1512-1518.

38. Hindle M, Newton DA, Chrystyn H. Investigations of an optimal inhaler technique with the use of urinary salbutamol excretion as a measure of relative bioavailability to the lung. Thorax. 1993;48(6):607-610.

39. Armour C, Bosnic-Anticevich S, Brillant M, Burton D, Emmerton L, Krass I, Saini B, Smith L, Stewart K.Pharmacy Asthma Care Program (PACP) improves outcomes for patients in the community. Thorax. 2007;62(6):496-502.

40. Hindle M, Chrystyn $\mathrm{H}$. Relative bioavailability of salbutamol to the lung following inhalation using metered dose inhalation methods and spacer devices. Thorax. 1994;49(6):549-553.

41. World Health Organization: Disease and injury country estimates. 2009. (accessed Sep-2010) http://www.who.int/healthinfo/global_burden_disease/estimates_country/en/index.html 